\title{
Electron Microscopy Education Outreach for Secondary and Professional Education
}

\author{
Greg Baty $^{1}$, Barbara Miner. ${ }^{2}$, E. Koehler ${ }^{2}$, Zhiqiang Chen ${ }^{1}$ \\ 1. Center for Electron Microscopy and Nanofabrication, Portland State University, Portland, OR 97221 \\ 2. Saturday Academy, Portland, OR 97203
}

In addition to university level Electron Microscopy courses with practical laboratory components, Center for Electron Microscopy and Nanofabrication (CEMN) offers outreach to professionals and high school students. Through our education efforts, students from junior / high school, university and industry have received intensive training in electron microscopy and related techniques.

Instrument vendors provide introductory instrument training when a microscope is purchased. Over time, staff attrition often affects a company's technical expertise. Professionals may not have access or time to take a traditional university course when on-the-job training is insufficient. Many universities have professional education outreach that helps industry maintain expertise. Lehigh is perhaps, the most well known for their highly structured microscopy short courses [1].

CEMN offers an 'Engineering Certificate in Applied Electron Microscopy' (ECAEM). The goal of the ECAEM program is to increase the competence of new and practicing microscopists, improving their ability to solve engineering related problems. To achieve this goal we provide a series of applicationbased short course lectures with intensive hands on labs, primarily to engineers and technicians in industry.

To improve participant's skills, specimens are selected that have sufficient complexity and artifacts to make interpretation of results difficult enough that students will question results. A portion of the labs are reserved for analyzing samples provided by the participants. Often participant samples are not optimal, so we help students find better preparation and analytical conditions. We find personal connection to the samples improves student engagement and helps professionals acquire new skills that immediately benefit the student and company. Positive results can be demonstrated by students identifying specific improvements that increase throughput, accuracy or improved analytical capabilities after taking the SEM course.

Partnering with Saturday Academy, we offer education outreach classes for high school students. Microscopy of common objects is an excellent introduction to scientific discovery. Students make discoveries deepening both their knowledge and curiosity. Project Micro [2] has proven methodologies for reaching large numbers of young students at low cost using optical microscopes and hand lenses. High school students are ready to be fascinated by the capabilities and complexities of SEM with compositional analysis. Generally high schools do not have the resources and expertise to operate or sustain a high school electron microscopy lab. However, there are notable exceptions such as Bergen County Academies NISL [3] and Project Nano [4]. Optimally outreach occurs in a university research lab, but table-top electron microscopes are an alternative that can reach more students.

We have found four critical components for high impact secondary education outreach: personal connection to the samples, contributing to important real world problem solving, personal ownership 
and presentation of results, and discussion of careers with passionate professionals.

Personal connection to samples: Through a few iterations of microscopy classes, we have found that students are highly motivated by samples that they have a connection with (e.g., hair from their own pets). We compared the results from two summer classes: one class studied pollens that were selected by the instructor to be 'photogenic' and the other class brought samples from home. All students were excited by doing hands-on microscopy. However, student engagement with the data from samples they had selected was much higher. Students willingly did extra research to gain more understanding of details seen in the images and created long lists of follow-on work.

Contribution to important and real world problem solving: As the students measure their own particles, we present data about EPA particulate matter classifications and the known health risks. We show a map of EPA- particle collection sites around the Portland area. For composition, we present data on how lead is detrimental to neurological development and a brief history of lead in paint and gas. This is presented as a scientific success, how scientists tracked down the roots of the problem, policy was changed and tested blood levels of lead in children dropped dramatically. Students connected their personal samples to the larger community and to the real world problem of lead exposure, increasing student engagement.

Individual presentation of results: The ability for each student to summarize his or her findings at the end of the class is a key element of learning. Presentation of results encourages students to take ownership of data and learning. As each student describes their "top 3" particles, they are entered by the instructor into the database of Portland particles. Students leave the class knowing that their work contributed to a public forum which increased their engagement and personal ownership.

Discussion of careers with professionals: It is important to have both female and male experts tell their personal career stories. Students can more easily imagine themselves as a scientist or engineer if they meet one. This type of intensive outreach can influence students at a time they are thinking of educational and career options. Figure 1 shows some of the free-form feedback of student's comments about the impact of our program.

\section{References}

[1] C. Lyman Microscopy and Microanalysis, 19 (Suppl. 2) (2013), 294-295.

[2] http://www.microscopy.org/education/projectMICRO/index.cfm

[3] http://research.bergen.org/index.php/nsil-lab-tour

[4] http://www.microscopy.org/MandM/2010/cady.pdf

[5] The authors thank Saturday Academy http://www.saturdayacademy.org/, Center for Electron Microscopy and Nanofabrication htpp://www.pdx.edu/cemn, for enabling these outreach activities.
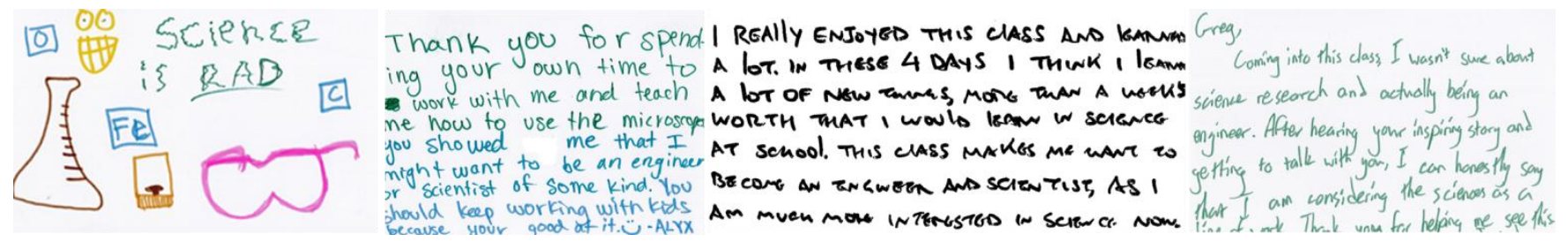